lies in inadequacy of method or simply inconclusive results: should one treat mild hypertension, although the (very large) MRC mild hypertension trial did not detect any clear effect on mortality?

ROBERT NEWCOMBE

University of Wales College of Medicine

Department of Medical Computing and Statistics

Heath Park

Cardiff CF 4 XN

This correspondence is now closed. I.P.

\section{Ordering thoughts in thought disorder}

SIR: McGrath proposes a hypothesis suggesting the involvement of frontal lobe dysfunction in schizophrenic thought disorder (Journal, March 1991, 158, 307-316). He argues mainly from the similarity between the pattern of language deficit in thought disorder and the pattern of cognitive-behavioura deficit in frontal lobe syndrome.

One further link between thought disorder and frontal lobe dysfunction is their association with eye tracking disorder. Among other symptoms and signs, thought disorder has one of the strongest associations with eye tracking disorder (Keefe et al, 1989). Eye tracking is controlled by a number of brain areas. One such area, thought to be affected in schizophrenia, is the frontal eye field (Fukushima $e t$ $a l, 1990)$, located in the prefrontal cortex.

Thought disorder encompasses a variety of phenomena. The proposed "prefrontal-basal ganglia loop" may account for only part of the diversity. Apart from the basal ganglia and the thalamus, the prefrontal cortex has reciprocal connections with the posterior association cortex, and limbic structures such as the hippocampus and the amygdala (Fuster, 1987). For example, one such area, the temporal cortex, is important in relation to category knowledge (e.g. Damasio, 1990). Categorisation is affected in some patients with thought disorder.

It seems plausible to propose that many prefrontal related loops (a distributed network radiating from the prefrontal area) including for instance, a prefrontal-temporal pathway, are affected in schizophrenic thought disorder. The different aspects of thought disorder (loosening of association, poverty of content of speech, etc.), may reflect differential dysfunction of these loops. It is important that studies relating thought disorder to brain mechanism take into account the various dimensions of thought disorder (rather than a global thought disorder measure), and study simultaneously a number of brain areas in order to capture some of the more subtle interactions.
DAmasio, A. R. (1990) Category-related recognition defects as a clue to the neural substrates of knowledge. Trends in Neuroscience, 13, 95-98.

Fukushima, J., Morita, N.. Fukushima, K.., et al (1990) Voluntary control of saccadic eye movements in patients with schizophrenic and affective disorders. Journal of Psychiatric Research, 24, 9-24.

Fuster, J. M. (1987) Prefrontal cortex. In Encyclopaedia of Neuroscience (ed. G. Adelman) pp. 972-975. Boston: Birkhauser.

Kefre, R. S., Siever, L. J., MoHs, R. C., el al (1989) Eye tracking, schizophrenic symptoms, and schizotypal personality disorder. European Archives of Psychiatry and Neurological Sciences, 239, $39-42$. Fulbourn Hospital
Cambridge

ERIC Y. H. CHEN

SIR: McGrath's review (Journal, March 1991, 158, 307-316) omitted mention of cognitive behaviour therapy strategies which are attracting increasing attention in the management of schizophrenia (e.g. Perris, 1989). The stages of therapy would appear to be rapport building, examination of the antecedents of psychotic breakdown, weighing of evidence, and reality testing, with generation of alternative hypotheses using a normalising rationale (Kingdon \& Turkington, 1991). Supplementary techniques include reduction of the emotional investment of psychotic symptoms and inference chaining to identify underlying schemata. These techniques seem to be most effective in conjunction with standard management regimes in the setting of a comprehensive psychiatric service. We describe the first reported use of these techniques in a thought-disordered hebephrenic patient.

Case report. A 22-year-old single man presented himself to our psychiatric reception area in a floridly thoughtdisordered state, with prominent paranoid delusions and incongruity of affect. These symptoms had worsened over a two-week period, during which time his sleep became progressively disturbed. He had experienced two schizophrenic episodes during the previous four years, which were treated with neuroleptics and cognitive therapy, and had returned to work on both occasions. No underlying disorder or history of drug abuse was detected. He was admitted, and treated with neuroleptics. Cognitive therapy sessions were included in his management programme. Rapport was established early but progress was impeded by intermingling of themes and derailment, which at times lapsed into incomprehensibility. He gave informed consent to the videotaping of an interview for teaching purposes. Review of this demonstrated that four clear themes were present. These were: references to a road traffic accident that he had witnessed, his mother's ill-health, concern about somatic symptoms of anxiety, and finally intermittent references to the videotaping process itself as being a form of experimentation. In relation to the latter, he commenced the interview by referring to his half-Jewish parentage and later 
specifically mentioned experimentation. These specific fears about the videotaping process were decatastrophised. After repeated revicwing, such references accounted for all areas that had previously appeared incomprehensible. Subsequent sessions had clear foci incorporating the sleep disturbance and stressful circumstances as a rationale to explain his symptoms. This may have contributed to a rapid improvement allowing him to be sent on extended leave from hospital within three weeks.

There are few references in the literature to therapeutic interventions for schizophrenic thought disorder (Birchwood et al, 1988). Yet such disorder is common and profoundly interferes with communication. It is a source of frustration to both patients and clinicians. Harrow \& Prosen (1978) demonstrated in a controlled manner that over $90 \%$ of intermingled material in schizophrenic thought disorder seemed to relate in some way to patients' personal experiences; this would therefore seem pertinent data for collaborative work between patient and therapist. Using audio and videotape for interviews may assist in clarifying the antecedents of psychotic breakdown from seemingly incomprehensible material. This is a crucial step in the process of cognitive therapy with these patients.

Birchwood, M., Hallett, S. \& Preston, M. (1988) Schizophrenia An Integrated Approach to Research and Treatment. London: Longman.

Harrow, M. \& Prosen, M. (1978) Intermingling and disordered logic as influences on schizophrenic 'thought disorders'. Archives of General Psychiatry, 35, 1213-1218.

Kingdon, D. \& TuRKIngton, D. (1991) The use of cognitive behaviour therapy with a normalizing rationale in schizophrenia. Journal of Nervous \& Mental Diseases, 4, 207-211.

PERris, C. (1989) Cognitive Therapy for Schizophrenic Patients. London: Cassell.

Bassetlaw District General Hospital

DOUglas TURKINGTON

DAVID G. KINGDON

Kilton

Worksop

Nottinghamshire S81 OBD

\section{Anabolic steroid use outside competition}

SIR: Previous correspondence has indicated the widespread use of anabolic steroids among athletes, alerting practitioners to their willingness to try new drugs offered by friends, and suggesting that anabolic steroid abuse as an aetiological factor should be suspected and objectively monitored (Choi \& Parrott, 1989). My own personal experience reinforces this warning. For several years I have trained regularly in busy gyms in Edinburgh, and during this time I have become aware of the surprising extent of anabolic steroid use at levels of ability and attainment far removed from the top class competitive arenas traditionally associated with drug abuse in sport (Williamson, 1991).

It is clear to me that the vast majority of anabolic steroid consumption occurs at 'grass roots' level among individuals never destined to compete, nor even aspiring to, but simply taking the drugs in order to improve their strength and physique. Contrary to the experience of Drs Choi \& Parrott, I have been astonished at the frank openness with which athletes have discussed their drug abuse. I too have been horrified to hear of misguided advice leading to, for example, ingestion of oestrogen antagonists in the belief that they are anabolic steroids, or salt tablets and aspirin to raise blood pressure and thin the blood' before a workout in the belief that this will force more blood into the muscles and give a better 'pump'. The recognition that anabolic steroid use is far more widespread than previously appreciated is also occurring in the USA (Yesalis et al, 1989), where it is now estimated that over one million people currently use anabolic steroids. Particularly worrying for Edinburgh practitioners, in the light of the high incidence of HIV infection among intravenous drug abusers in this city, is the news that athletes have caught AIDS from injecting anabolic steroids with infected needles (Sklarek et al, 1984).

As psychiatrists, we should be concerned at news of the epidemic growth of anabolic steroid use in this country in the light of recent reports of a high incidence of aggression and frank psychiatric symptoms (Pope \& Katz, 1988), and also dependency (Yesalis et al, 1989) among steroid users. Perhaps we shall soon be including urine 'dope tests' among our routine investigations for organic precipitants of psychiatric illness. I am planning further research on this unique group of individuals.

Choi, P. \& PARrott, A. (1989) Illicit drug use in strength athletes. British Journal of Psychiatry, 154, 732.

POPE, H. G. \& KATZ, D. L. (1988) Affective and psychotic symptoms associated with anabolic steroid use. American Journal of Psychiatry, 145, 487-490.

Sklarex, H., Mantovani, R., Erens, E., et al (1984) AIDS in a bodybuilder using anabolic steroids. New England Journal of Medicine, 311, 1701.

Willakson, D. J. (1991) Anabolic steroids: Edinburgh's lesser known drug problem. Edinburgh Medicine, 65, 6-7.

Yesal.is, C. E., Streit, A. L., Vicary, J. R., el al (1989) Anabolic steroid use: indications of habituation among adolescents. Journal of Drug Education, 19, 103-116.

\section{State Hospital}

Douglas Williamson

Lanark 